\title{
Increased psychological distress among individuals with spinal cord injury is associated with central neuropathic pain rather than the injury characteristics
}

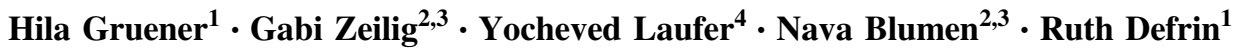 \\ Received: 1 June 2017 / Revised: 14 August 2017 / Accepted: 19 August 2017 / Published online: 14 December 2017 \\ (C) International Spinal Cord Society 2018
}

\begin{abstract}
Study design Cross-sectional study.

Objectives Central neuropathic pain (CNP) is common after spinal cord injury (SCI). The psychological impact of CNP is not clear. Previous studies reported depression and pain catastrophizing among patients with SCI and CNP; however, the lack of control groups prevented discerning whether these were attributed to CNP or to the SCI itself. The aim was to examine the psychological distress among individuals with SCI with and without CNP and controls to evaluate its impact and possible source.
\end{abstract}

Setting Outpatient clinic of a large rehabilitation center.

Methods Individuals with SCI and CNP $(n=27)$ and without CNP $(n=23)$, and able-bodied controls $(n=20)$ participated. Data collection included sociodemographics, SCI characteristics, and level of post-traumatic stress disorder (PTSD), anxiety, stress, depression, and pain catastrophizing. The sensory, affective, and cognitive dimensions of CNP were analyzed.

Results Individuals with SCI and CNP exhibited elevated levels of PTSD, anxiety, stress, depression, and pain catastrophizing compared to the two control groups, which presented similar levels. The psychological variables among the CNP group correlated positively only with the affective dimension of CNP. Neither CNP nor the psychological variables correlated with SCI characteristics.

Conclusions Irrespective of CNP intensity, the affective dimension (suffering) is associated with increased psychological distress. Perhaps individual differences in the response to SCI and/or individual traits rather than the mere exposure to SCI may have a role in the emergence of CNP and psychological distress/mood dysfunction. Rehabilitation programs should prioritize stress management and prevention among individuals with SCI and CNP.

Ruth Defrin

rutidef@post.tau.ac.il

1 Department of Physical Therapy at Sackler Faculty of Medicine, and Sagol School of Neuroscience, Tel Aviv University, Tel Aviv, Israel

2 Department of Neurological Rehabilitation, Chaim Sheba Medical Center, Tel Hashomer, Israel

3 Department of Rehabilitation Sackler Faculty of Medicine, Tel Aviv University, Tel Aviv, Israel

4 Physical Therapy Department, University of Haifa, Haifa, Israel

\section{Introduction}

Spinal cord injury (SCI) is a traumatic event that impairs sensory, autonomic, and/or motor function. As such, SCI may also lead to long-term psychological sequels such as post-traumatic stress disorder (PTSD) [1-7], anxiety, and distress $[2,4,8]$. Studies suggest that traumatic events may lead to the co-existence of PTSD and chronic pain [9-11] yet only a few studies documented this co-existence among individuals with SCI. In two cross-sectional studies, PTSD symptomatology correlated with chronic pain severity $[12,13]$. In one longitudinal study, co-morbid pain and PTSD symptoms were more common than either condition alone but PTSD did not necessarily correlate with pain 
intensity [7]. Other studies have also reported that pain catastrophizing and/or pain interference [8, 14-22] correlated positively with chronic pain severity, and that pain interference correlated with quality of life [23]. It is important to note, however, that most of the aforementioned studies did not include a control group of individuals with SCI who do not suffer from chronic pain. Therefore, it is not clear whether these psychological variables are related to the chronic pain or the SCI itself.

Among the many types of chronic pain that develop following SCI [24], central neuropathic pain (CNP) is considered the most debilitating. CNP is defined as a pain caused by a lesion/disease of the central somatosensory nervous system (e.g., trauma, tumors, and infection) [25]. CNP that occurs in about $50 \%$ of the individuals with SCI [26-29] is often severe and excruciating, and in contrast to other SCI-induced chronic pain types, CNP is relatively refractory to pharmacological, surgical, physical, and behavioral interventions [30-34]. Therefore, CNP has significant deleterious effects on daily activities, quality of life, and rehabilitation. As CNP is particularly prevalent following a traumatic SCI [35], its association with the possible psychological sequels of traumatic events is of particular interest.

Although several studies have reported that individuals with SCI and chronic pain exhibit higher levels of anxiety and depression compared to pain-free individuals $[8,20,36-38]$, these studies included all types of chronic pain with no specific reference to CNP. We could find only four studies in this regard, showing an association between CNP severity and depression [39] or pain catastrophizing [40-42]. However, none of the studies compared the psychological variables among individuals post SCI with CNP to individuals with SCI without CNP, or to able-bodied controls. Here again, it is not clear whether the psychological variables could be attributed solely to the presence of CNP or to the SCI.

Given the dearth of information on the psychological impact of CNP, the aim was to examine among individuals with SCI with and without CNP, and able-bodied controls: (1) the level of PTSD and psychological distress, and (2) the association between these variables and variables related to the CNP and the SCI.

\section{Methods}

\section{Subjects}

The study included three groups: individuals with SCI and CNP (SCIP), individuals with SCI without CNP (SCINP), and sex-matched and age-matched able-bodied controls (AC). Individuals with SCI were recruited by phone calls to eligible patients listed at the outpatient clinics of the Department of Neurological Rehabilitation at Sheba Medical Center, Tel Hashomer, Israel. AC were recruited among employees of Tel Aviv University and Sheba Medical Center by way of advertisements.

Inclusion criteria for SCIP and SCINP were: (1) Complete or incomplete SCI >1-year duration; (2) SCI above T12 to avoid lesions to the conus medullaris and cauda equine that may have peripheral involvement, and below C3. Inclusion criteria specific for SCIP: (1) CNP $>6$-months duration at or below the level of injury, (2) no pathologies other than the SCI that might underlie the pain (e.g., peripheral neuropathy). Inclusion criteria for AC: (1) lack of any acute or chronic pain, (2) lack of chronic diseases.

Exclusion criteria for all subjects were: (1) medical conditions with potential neural damage (e.g., diabetes mellitus), (2) history of severe neurological disorders other than SCI (e.g., multiple sclerosis, traumatic brain injury), (3) concurrent severe medical conditions, and (4) psychiatric or cognitive status that might interfere with testing.

CNP was determined by the clinical neurological examination based on its definition and characteristics [43]. These include spontaneous and/or evoked burning, stabbing, or shooting pain located in diffuse body regions more than three dermatomes below the neurological level of injury (for below-level pain) and/or located within the dermatome of the level of neurological injury and three dermatomes below this level (for at-level pain).

The study was approved by the Human Ethics Committees of Sheba Medical Center and of Tel Aviv University. Written informed consent was obtained from all subjects, after a complete explanation of the study protocol and goals were provided. We certified that all applicable institutional and governmental regulations concerning the ethical use of human volunteers were followed during the course of this research.

\section{Questionnaires}

\section{Chronic pain}

The McGill Pain Questionnaire (MPQ) provides a quantitative evaluation of the subject's pain experience with separate measures for the sensory, affective, and cognitive dimensions. Two major quantitative parameters are derived: (1) the number of words chosen (NWC) by the subject from a list of descriptors, and (2) the pain rating index (PRI)based on summing the rank values of these words. These parameters are calculated as total scores and as scores of the sensory, affective, and cognitive dimensions, separately. Descriptors of the sensory dimension of pain relate to temporal, spatial, pain quality, and similar properties 
(e.g., burning, sharp, pricking). Descriptors of the affective dimension relate to tension, fear, and emotional reaction (e.g., hurting, exhausting, terrifying). Descriptors of the cognitive-evaluative dimension relate to the degree of interference and tolerability of the pain (e.g., troublesome, annoying) [44].

\section{Post-traumatic stress disorder}

The PTSD Questionnaire is composed of 17 items describing different symptoms based on the Diagnostic and Statistical Manual for Mental Disorders, 4th ed. criteria for PTSD, evaluating post-traumatic stress symptomatology [45]. Respondents indicate, on a four-point Likert scale (from 1 to 4 ), the extent to which they experience these symptoms (score range: 17-68). The inventory has good convergent validity when compared with structured clinical interviews ( $\alpha$-Cronbach's $=0.89$ in the present study).

\section{Stress}

The Perceived Stress Scale (PSS) is composed of 10 items that measure the degree to which situations in one's life over the past month are appraised as stressful, unpredictable, or uncontrollable [46]. Respondents indicate, on a five-point Likert scale (from 0 to 4 ) how often they felt a certain way in each case (score ranges: 0-40). Higher scores indicate higher degree of self-perceived stress [10] ( $\alpha$-Cronbach's herein $=0.87$ ).

\section{Anxiety}

The State-Trait Anxiety Inventory (STAI) is composed of 10 items; five are indicators for anxiety (e.g., tense, upset), and five are reversed items [47]. Respondents indicate, on a four-point Likert scale (from 1 to 4 ), the extent to which they usually feel these emotions (score ranges: 0-40). A higher score reflects a higher level of anxiety ( $\alpha$-Cronbach's herein $=0.82$ ).

\section{Depression}

The Depression Anxiety Stress Scale (DASS21) is composed of 21 items that measure distress along the axes of depression, anxiety, and stress (7 items per scale) [48]. Respondents rate, on a four-point severity/frequency scale (from 0 to 3 ), the extent to which they have experienced each state over the past week (score ranges: 0-63). Scores are calculated separately for depression, anxiety, and stress. Owing to the redundancy between the anxiety and stress parts of the DASS and the above-mentioned questionnaires, only the depression section of the questionnaire was analyzed $(\alpha$-Cronbach's herein $=0.95)$.

\section{Pain catastrophizing}

The Pain Catastrophizing Scale (PCS) is composed of 13 items that measure pain-related reactions: rumination, magnification, and helplessness [49]. Respondents reflect on past painful experiences and indicate the degree to which they experienced each of 13 thoughts or feelings when experiencing pain, on a five-point Likert scale from 0 to 4 (score ranges: $0-52 ; \alpha$-Cronbach's herein $=0.90$ ).

\section{Data collection}

All data were obtained in a single visit. All subjects underwent a brief structured interview by a researcher (author H.G.) to obtain sociodemographic data (age, sex, living with significant other, and employment). Subjects with SCI were also questioned about the SCI (time since injury, level of injury-tetraplegia/paraplegia, cause of injury-motor vehicle accident/fall from height/ gunshot/other, and medication intake). These variables, as well as the results of the American Spinal Injury Association Impairment Scale (AIS)-A/B/C/D, were then confirmed using the subjects' medical records. All subjects completed the aforementioned questionnaires. Subjects with CNP also completed the MPQ and were questioned about pain onset, duration, quality, location in the body (on a body chart), use of medication, and alleviating and aggravating factors.

\section{Data analysis}

Data were processed using IBM SPSS statistics software (version 23). Analyses of variance (ANOVA) with interactions and corrected post-hoc comparisons were used to evaluate group effect (SCIP, SCINP, AC) on the psychological, sociodemographic, and SCI-related variables. Pearson's and Spearman's tests were used to calculate correlation coefficients between CNP variables (total and subscales of the MPQ) and psychological variables, sociodemographics and SCI variables. In addition, a discriminant function analysis was used to examine the prediction of group type by the psychological (predictor) variables. Although both discriminant function analysis and logistic regression are used for prediction, the former is used specifically to predict a categorical dependent variable (grouping variable), when groups are known a priori. It can also be used with relatively small sample sizes [50]. Each variable was entered directly into the analysis as no a priori assumption had been made regarding the relative contribution of the variables. $p$-values $<0.05$ were considered statistically significant. 
Table 1 Characteristics of the study groups

\begin{tabular}{|c|c|c|c|c|}
\hline & $\begin{array}{l}\text { SCIP } \\
(n=27)\end{array}$ & $\begin{array}{l}\text { SCINP } \\
(n=23)\end{array}$ & $\begin{array}{c}\mathrm{AC} \\
(n=20)\end{array}$ & $p$-value* \\
\hline $\begin{array}{l}\text { Age (mean } \pm S D \\
\text { years) }\end{array}$ & $\begin{array}{l}48.4 \\
(14.3)\end{array}$ & $42.3(14.2)$ & $\begin{array}{l}44.15 \\
(16.6)\end{array}$ & 0.339 \\
\hline Sex (males/females) & $23 / 4$ & $22 / 1$ & $15 / 5$ & 0.159 \\
\hline $\begin{array}{l}\text { Living with } \\
\text { significant other } \\
\text { (yes, \%) }\end{array}$ & $20(74 \%)$ & $12(52 \%)$ & $14(70 \%)$ & 0.073 \\
\hline Employment (yes, \%) & $8(30 \%)$ & $10(43 \%)$ & $\begin{array}{c}20 \\
(100 \%)^{\mathrm{a}}\end{array}$ & 0.001 \\
\hline $\begin{array}{l}\text { Time since injury } \\
\text { (mean } \pm \mathrm{SD} \text {, years) }\end{array}$ & $19(15.7)$ & $18.4(14.5)$ & - & 0.894 \\
\hline \multicolumn{5}{|l|}{ Level of injury (\%) } \\
\hline Tetraplegia & $4(15 \%)$ & $5(22 \%)$ & - & 0.529 \\
\hline Paraplegia & $23(85 \%)$ & $18(78 \%)$ & & \\
\hline Cause of injury (\%) & & & - & 0.354 \\
\hline $\begin{array}{l}\text { Motor vehicle } \\
\text { accident }\end{array}$ & $14(52 \%)$ & $15(65 \%)$ & & \\
\hline Fall from height & $5(18 \%)$ & $3(13 \%)$ & & \\
\hline Gunshot & $3(11 \%)$ & $2(9 \%)$ & & \\
\hline Other & $5(18 \%)$ & $3(13 \%)$ & & \\
\hline AIS (\%) & & & - & 0.909 \\
\hline A & $16(59 \%)$ & $14(61 \%)$ & & \\
\hline $\mathrm{B}$ & $4(15 \%)$ & $3(13 \%)$ & & \\
\hline $\mathrm{C}$ & $6(22 \%)$ & $6(26 \%)$ & & \\
\hline $\mathrm{D}$ & $1(3.7 \%)$ & $0(0 \%)$ & & \\
\hline
\end{tabular}

$A C$ able-bodied controls, $A I S$ American Spinal Injury Association Impairment Scale, SCINP individuals with SCI without CNP, SCIP individuals with SCI and CNP, SD standard deviation

*Comparison between the groups (parametric and non-parametric tests according to the variables)

${ }^{\mathrm{a} B e t w e e n ~} \mathrm{AC}$ and each of the SCI groups

Significant correlations are marked in bold

\section{Results}

\section{Characteristics of the study groups}

Table 1 describes the characteristics of the groups. Participants of three groups, SCIP, SCINP, and AC, did not differ in age, sex distribution, and family status except that more members of the AC group were employed. The two SCI groups (SCIP and SCINP) did not differ in SCI-related variables. Subjects in both these groups reported taking medications for various conditions, including high blood pressure $11 \%$ and $4 \%$, respectively), high cholesterol (7\% and $17 \%$ ), and muscle spasms (37\% and 35\%), with no significant group differences. Analgesic medications intake was reported by $81 \%$ of subjects in the SCIP group, including medical marijuana (41\%), anti-epileptics (37\%), opioids $(18 \%)$, serotonin/noradrenaline reuptake
Table 2 The total pain intensity and the sensory, affective and evaluative aspects of pain intensity of the SCIP group based on the McGill pain questionnaire

\begin{tabular}{lllll}
\hline & Total & Sensory & Affective & Evaluative \\
\hline NWC & $8.7 \pm 4.5$ & $6.4 \pm 3.2$ & $1.2 \pm 1.3$ & $1.1 \pm 0.5(0-2)$ \\
& $(1-17)$ & $(1-11)$ & $(0-4)$ & \\
PRI & $20.5 \pm 11$ & $14.5 \pm 7.8$ & $2.6 \pm 2.7$ & $3.3 \pm 2.3(0-8)$ \\
& $(3-45)$ & $(2-30)$ & $(0-8)$ & \\
\hline
\end{tabular}

$N W C$ the number of words chosen, $P R I$ pain rating index

Average score, SD and range for the NWC and PRI indices of the McGill Pain Questionnaire

inhibitors (15\%), and non-steroidal anti-inflammatory drugs $(15 \%)$.

\section{Characteristics of CNP}

Within the SCIP group, 13 had below-level pain, 1 had atlevel pain, and 13 had both types. Table 2 describes the total and subscale scores of the MPQ indices. Subjects had an average of $6.2 \pm 3$ painful body regions with the most frequent being the thigh $(20 / 74 \%)$ followed by the shin (17/ $63 \%)$, feet $(15 / 55.5 \%)$, lower back (11/40.7\%), upper back $(8 / 30 \%)$, buttocks $(6 / 22 \%)$, and abdomen $(3 / 11.1 \%)$. The qualities of CNP based on the MPQ were in decreasing order: radiating $(20 / 74 \%)$, sharp $(19 / 70 \%)$, burning (13/ $48 \%)$, stinging $(11 / 41 \%)$, stabbing/penetrating $(9 / 33 \%)$, and beating $(7 / 26 \%)$. Aggravating factors of CNP were: extended sitting/lying (14/52\%), changing/cold weather (13/ $48 \%)$, illness or physical exercise $(4 / 15 \%)$, fatigue $(3 / 11 \%)$, etc. Alleviating factors were: medications (20/74\%), resting/ lying down $(7 / 26 \%)$, and physical exercise $(5 / 19 \%)$.

\section{Psychological variables}

Figure 1 presents the psychological variables among the three groups. There was a significant effect of group type on all the variables; PTSD: $\left(\mathrm{F}_{(2,67)}=5.66, p<0.01\right)$; anxiety: $\left(\mathrm{F}_{(2,67)}=7.26, p<0.01\right)$; perceived stress: $\left(\mathrm{F}_{(2,67)}=4.33, p\right.$ $<0.05)$; depression $\left(\mathrm{F}_{(2,66)}=4.9, p<0.01\right)$, and pain catastrophizing: $\quad\left(\mathrm{F}_{(2,67)}=3.23, \quad p<0.05\right)$. Post-hoc tests revealed that the SCIP group scored significantly higher on all variables, compared to both the SCINP and AC groups, but the two latter groups did not differ from one another (Fig. 1).

\section{Correlations between CNP and psychological variables}

As there was a strong significant correlation between the NWC and PRI indices of the MPQ in total and subscale scores $(r>0.95, p<0.0001)$, we chose NWC for further analyses representing the chronic pain. Table 3 presents the 
Fig. 1 Mean values of PTSD symptomatology and psychological distress. An elevated level of PTSD symptomatology and psychological distress is observed among SCIP group compared to both SCINP and AC groups. The latter two groups did not differ. $* p<0.05$, $* * p<0.01, * * * p<0.001$. Values denote group mean \pm SEM

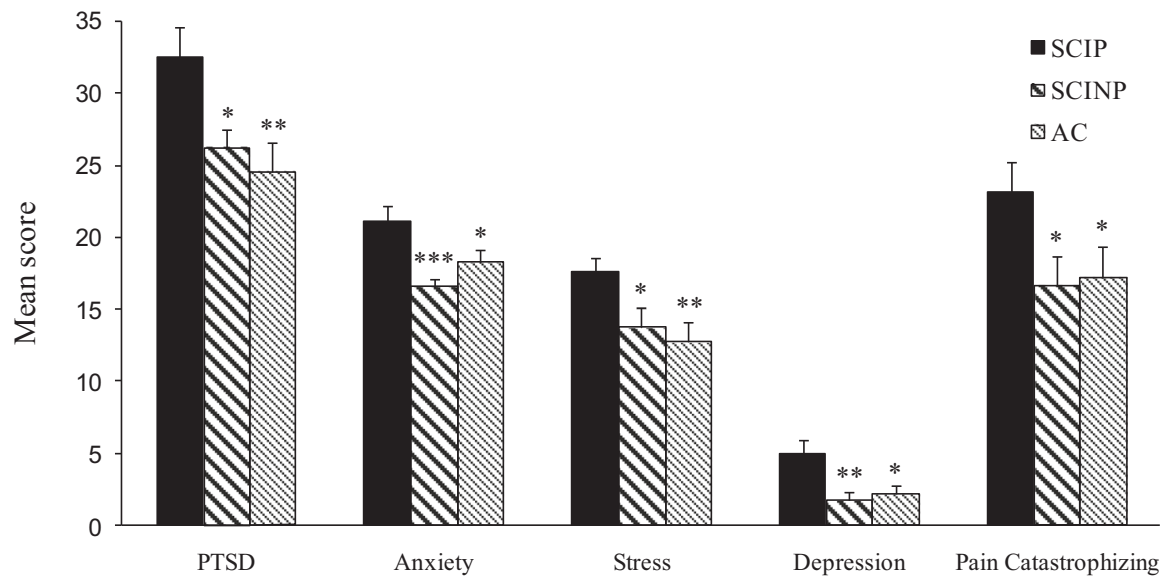

correlation coefficients between the total and subscale scores of NWC and between the psychological variables. The total NWC score correlated only with depression; the stronger the pain the higher the depression level. Out of the MPQ subscales, only the affective subscale correlated positively with most of the psychological variables; the stronger the affective dimension of pain, the higher the posttraumatic symptoms, anxiety, stress, and depression (with a trend for pain catastrophizing).

\section{Other correlations}

CNP did not correlate with SCI variables (time since injury, cause, level, and completeness) or the sociodemographic variables (marital status, employment, etc.) except for age $(r=-0.52, p<0.01)$; older subjects had weaker CNP intensity (total score). Among both SCI groups, the psychological variables did not correlate with any of the SCI variables or the sociodemographic variables, except for an association with employment in the SCINP group only; compared to individuals who were employed, unemployed individuals had more PTSD $(36.3 \pm 10.2$ vs. $26.3 \pm 4.7, p$ $<0.05)$, anxiety $(23.5 \pm 6.1$ vs. $18.8 \pm 2.2, p<0.05)$, perceived stress $(19.4 \pm 5.7$ vs. $13.6 \pm 5.6, p<0.05)$, depression $(6.5 \pm 5.6$ vs. $2.4 \pm 2, \quad p=0.05), \quad$ and pain catastrophizing $(26.6 \pm 8.6$ vs. $17.8 \pm 10.4, p<0.05)$.

\section{Discriminant function analysis}

The discriminant analysis resulted in one significant discriminant function (function 1 : $\chi^{2}(10)=18.657, \lambda=0.736$, $p<0.05)$ indicating that the SCIP group differed from the control groups. The second, non-significant function (function $2: \chi^{2}(4)=4.462, \lambda=0.93, p=0.35$ ) indicated no additional discriminations. The eigenvalues associated with the discriminant functions indicated that $78 \%$ of the between-group variability was accounted for by the first discriminant function. The centroid values of the discriminant function $1(0.62,-0.49$, and -0.26 for SCIP, SCINP, and AC, respectively) indicated that this equation discriminated between the CNP group, who scored the highest loaded values, and the control groups who had lower scores (Table 4, upper panel).

The first function was able to correctly classify $60 \%$ of the SCIP subjects, $62 \%$ of the SCINP subjects, and $70 \%$ of the AC suggesting good discrimination ability. Table 4 (lower panel) presents the variable loadings on the discriminant function; the larger the variable loading, the more the variable contributed to the prediction of group membership. A pooled within-groups correlation between discriminating variables and the canonical discriminant function of 0.20 constituted the threshold of a predicting variable [50]. Thus, PTSD, anxiety, and depression made the most substantial contributions to the discrimination between the SCIP subjects and the two control groups.

\section{Discussion}

\section{Increased PTSD and psychological distress in CNP}

To the best of our knowledge, this is the first study that found elevated levels of PTSD symptomatology, anxiety, perceived stress, depression, and pain catastrophizing among individuals with CNP compared to controls. Importantly, although both individuals with SCI with and without CNP underwent significant traumatic events that led to the SCI, and despite sharing similar injury characteristics, only the former had high levels of PTSD and psychological distress. Moreover, the discriminant analysis showed that anxiety, depression, and PTSD differentiated between individuals with CNP and the two control groups who were indistinguishable. Therefore, elevated distress and mood dysfunction are associated with the presence of CNP among individuals with SCI.

Our results agree with studies in which anxiety and/or depression among individuals with SCI and chronic pain of 
Table 3 Correlations between CNP dimensions (assessed by NWC) and psychological variables

\begin{tabular}{llllll}
\hline CNP dimensions & PTSD & Anxiety & Perceived stress & Depression & Pain catastrophizing \\
\hline Total & 0.25 & 0.31 & 0.23 & $\mathbf{0 . 4 6}^{*}$ & 0.02 \\
Affective & $\mathbf{0 . 4 0}$ & $\mathbf{0 . 5 5} \mathbf{5}^{* *}$ & $\mathbf{0 . 5 0 * *}$ & $\mathbf{0 . 5 4 * *}$ & $\mathbf{0 . 3 4}^{\wedge}$ \\
Sensory & 0.14 & 0.18 & 0.08 & 0.36 & -0.08 \\
Evaluative & 0.28 & 0.15 & 0.17 & 0.34 & -0.015 \\
\hline
\end{tabular}

${ }^{*} p<0.05,{ }^{* *} p<0.01,{ }^{\wedge} p=0.06$, two-tailed. Significant correlations are marked in bold unspecified origin, were higher compared to those who were pain-free $[8,20,36-38]$, supporting the possibility that psychological distress may be related to chronic pain rather than the SCI. The results corroborate studies reporting comorbidity of PTSD and chronic pain after traumatic events [9-11] and after SCI $[7,12,13]$. Owing to the nature of the present study, we cannot determine whether the PTSD and psychological distress preceded the CNP or whether they resulted from it. Considering that CNP develops within months after a SCI [27, 51-53], the first possibility is viable. Ullrich et al. [7] reported that individuals with acute SCI, who at baseline exhibited PTSD alone, experienced an increase in pain levels over time. In another longitudinal study, Jenewein et al. [54] reported a mutual impact of pain and PTSD symptoms within the first 6 months after injury, whereas in the second 6 months, increased pain intensity was predicted by higher PTSD symptoms, but not vice versa. Although further study is necessary to prove causality, these studies suggest that PTSD symptomatology and related distress may precede chronic pain after SCI and perhaps also preceded the CNP among the individuals herein.

Alternatively, it is also possible that another, predisposing factor was responsible for the emergence of both the psychological distress and CNP. For example, several studies have suggested that the anxiety sensitivity construct may represent the shared vulnerability between PTSD and chronic pain in the aftermath of trauma [9, 10]. This possible predisposing factor was also suggested to underlie the maintenance of PTSD and chronic pain over time [10]. Accordingly, the possible mutual development of PTSD and CNP after the SCI may have occurred in susceptible individuals, a hypothesis that is yet to be proven.

Interestingly, the CNP characteristics did not correlate with SCI characteristics including level of injury, AIS score and cause of injury. This finding is in agreement with previous studies $[27,55,56]$. The finding further support the role of the psychological sequel of SCI, or alternatively the psychological predisposition, in the emergence and perhaps in the chronification of CNP.

\section{The role of the affective dimension of $\mathrm{CNP}$}

A positive correlation was found between total CNP magnitude and depression, which is in agreement with Kilic et al. [39] The additional psychological variables did not correlate with total CNP magnitude, although other studies reported an association between pain catastrophizing and CNP intensity, measured with a numerical rating scale [40-42]. When we divided the total CNP experience into its sensory, affective and cognitive dimensions, all the psychological variables (a trend for pain catastrophizing) correlated significantly and positively with the affective dimension. This differential effect emphasizes the unique features of each pain dimension.

The sensory dimension of pain is subserved, at least in part, by the lateral nociceptive system, which projects through specific lateral thalamic nuclei and has the ability to process information about the spatial, temporal, and magnitude of the nociceptive input [57, 58]. The affective dimension of pain is probably subserved by the medial nociceptive system that projects through medial thalamic nuclei and gains access to the limbic system. This system is known to process the aversiveness of the pain experience and emotional reactions, as well as arousal and attentional biases to pain $[57,58]$.

The most frequent affective descriptors from the MPQ, chosen by the individuals with CNP were exhausting, agonizing, and cruel. It is understandable that the affective dimension of CNP correlated with the magnitude of the individuals' stress, anxiety, and depression; however, it is interesting that this correlation occurred irrespective of how strong (sensory aspect) the CNP was. Studies have found that the affective dimension of pain was more central in chronic pain, whereas the sensory was more central in experimental and acute pain [59-62]. Thus, the affective dimension may become dominant in uncontrollable, threatening conditions. The burden of CNP on individuals with SCI, who already experience some degree of functional loss, can further increase the sense of uncontrollability and unpredictability, namely of distress [63] and vice versa, increased distress may further enhance the suffering from the pain. 
Table 4 Values of the two discriminant functions and variable loadings of the discriminant function 1

\begin{tabular}{|c|c|c|c|c|}
\hline \multicolumn{5}{|l|}{ Discriminant functions } \\
\hline \multicolumn{2}{|l|}{ Group } & \multicolumn{2}{|c|}{ Function 1} & Function 2 \\
\hline SCIP & & 0.629 & & 0.064 \\
\hline SCINP & & -0.498 & & 0.289 \\
\hline $\mathrm{AC}$ & & -0.264 & & -0.383 \\
\hline \multicolumn{5}{|l|}{ Variable loading } \\
\hline Predictor variable & \multicolumn{2}{|c|}{$\begin{array}{l}\text { Standardized canonical } \\
\text { discriminant function coefficient }\end{array}$} & \multicolumn{2}{|l|}{$\begin{array}{l}\text { Pooled within-groups correlation between } \\
\text { discriminating variables and canonical } \\
\text { discriminant function }\end{array}$} \\
\hline PTSD & 0.3 & & 0.822 & \\
\hline Anxiety & 0.52 & & 0.886 & \\
\hline Perceived stress & 0.0 & & 0.594 & \\
\hline Depression & 0.25 & & 0.801 & \\
\hline Pain catastrophizing & 0.03 & & 0.606 & \\
\hline Canonical $R$ & 0.46 & & & \\
\hline Eigenvalue & 0.26 & & & \\
\hline$\%$ of variance & $76 \%$ & & & \\
\hline
\end{tabular}

$A C$ able-bodied controls, PTSD post-traumatic stress disorder, SCINP spinal cord injury patients without neuropathic pain, SCIP spinal cord injury patients with central neuropathic pain
Among patients with acute SCI, Taylor et al. [14] found an association between pain catastrophizing and the sensory and affective dimensions of pain. To the best of our knowledge, only one other study examined the different chronic pain dimensions among individuals with chronic SCI. Giardino et al. [15] reported that pain catastrophizing and depression correlated with both the sensory and affective dimensions of (non-specific) chronic pain, although the strength of the latter association was twice that of the former. Other studies on patients with fibromyalgia and peripheral neuropathic pain, confirmed the association between pain catastrophizing and the affective, but not sensory dimension of pain [64, 65]. This corresponds with our finding that the affective dimension contributed more strongly to the individual's suffering and distress.

Importantly, none of the psychological variables correlated with SCI characteristics which is in agreement with other reports [7, 13, 14, 16, 17]. The discriminant analysis indeed showed that increased PTSD and psychological distress were unique to the CNP group despite that they shared similar injury characteristics to those of pain-free individuals with SCI. Perhaps this finding and the fact that the latter were indistinguishable from the $\mathrm{AC}$ group support the possibility, that it is individual differences in the response to trauma rather than the mere exposure to the trauma that matters. Social factors such as employment may also contribute to individuals' response. Increased PTSD symptomatology, anxiety, stress, depression, and pain catastrophizing were seen herein among unemployed vs. employed individuals with CNP; an association that was not seen among pain-free individuals.

\section{Conclusions and implications}

The results suggest that among individuals with SCI, PTSD symptomatology, psychological distress (anxiety, stress and depression), and pain catastrophizing are associated with the affective dimension of CNP (suffering), regardless of the sensory dimension (intensity); the more suffering due to CNP the higher the psychological distress. These results should be considered in light of several limitations. First, members of the CNP group used analgesic medications that may affect chronic pain intensity. Second, the study was cross-sectional, which prevented us from determining whether CNP preceded the psychological distress or vice versa or whether both emerged due to another predisposing factor. Future, longitudinal studies may answer this question.

Despite these limitations, the results imply that individual differences in the response to SCI and/or individual traits rather than the mere exposure to SCI have a role in the emergence of psychological distress and CNP. The co-existence of these conditions entails a major burden on the individual and may render the individual more prone to developing additional pathological conditions [10, 66]. Therefore, rehabilitation programs for people with SCI 
should prioritize management of CNP and distress already in the acute phase as well as careful, long-term monitoring of these conditions.

\section{Data archiving}

All relevant data are within this manuscript and raw data are archived by the authors.

Acknowledgements This study was performed in partial fulfillment of the requirements for a $\mathrm{PhD}$ degree in Physical Therapy by Hila Gruener at the Sackler Faculty of Medicine, Tel Aviv University, Tel Aviv, Israel. This work was supported by the International Foundation for Research in Paraplegia (IRP) (Grant Number P156) and the National Insurance Association (Grant Number 164412).

\section{Compliance with ethical standards}

Conflict of interest The authors declare that they have no competing interests.

\section{References}

1. Pollock K, Dorstyn D, Butt L, Prentice S. Posttraumatic stress following spinal cord injury: a systematic review of risk and vulnerability factors. Spinal Cord. 2017;55:800-11.

2. Nielsen MS. Post-traumatic stress disorder and emotional distress in persons with spinal cord lesion. Spinal Cord. 2003;41:296-302.

3. Migliorini CE, Tonge BJ, Taleporos G. Spinal cord injury and mental health. Aust N Z J Psychiatry. 2008;42:309-14.

4. Banerjea R, Findley PA, Smith B, Findley T, Sambamoorth U. Co-occurring medical and mental illness and substance use disorders among veteran clinic users with spinal cord injury patients with complexities. Spinal Cord. 2009;47:789-95.

5. Krause JS, Saunders LL, Newman S. Posttraumatic stress disorder and spinal cord. Arch Phys Med Rehabil. 2010;91:1182-87.

6. Abeyasinghe NL, de Zoysa P, Bandara KMKC, Bartholameuz NA, Bandara LMUJ. The prevalence of symptoms of posttraumatic stress disorder among soldiers with amputation of a limb or spinal injury: a report from a rehabilitation center in Sri Lanka. Psychol Health Med. 2012;73:376-81.

7. Ullrich PM, Smith BM, Poggensee L, Evans CT, Stroupe KT, Weaver FM, et al Pain and post-traumatic stress disorder symptoms during inpatient rehabilitation among operation enduring freedom/operation Iraqi freedom veterans with spinal cord injury. Arch Phys Med Rehabil. 2013;94:80-5.

8. Wollaars MM, Post MW, van Asbeck FW, Brand N. Spinal cord injury pain: the influence of psychologic factors and impact on quality of life. Clin J Pain. 2007;23:383-91.

9. Sharp TJ, Harvey AG. Chronic pain and posttraumatic stress disorder: mutual maintenance? Clin Psychol Rev. 2001;21:857-77.

10. Asmundson GJ, Katz J. Understanding the co-occurrence of anxiety disorders and chronic pain: state-of-the-art. Depress Anxiety. 2009;26:888-901.

11. Moeller-Bertram T, Keltner J, Strigo IA. Pain and posttraumatic stress disorder-review of clinical and experimental evidence. Neuropharmacology. 2012;62:586-97.

12. Martz E, Livneh H, Priebe M, Wuermser LA, Ottomanelli L. Predictors of psychosocial adaptation among people with spinal cord injury or disorder. Arch Phys Med Rehabil. 2005;86:1182-92.

13. Otis C, Marchand A, Courtois F. Risk factors for posttraumatic stress disorder in persons with spinal cord injury. Top Spinal Cord Inj Rehabil. 2012;18:253-63.

14. Turner JA, Jensen MP, Warms A, Cardenas DD. Catastrophizing is associated with pain intensity, psychological distress, and pain related disability among individuals with chronic pain after spinal cord injury. Pain. 2002;98:127-34.

15. Giardino ND, Jensen MP, Turner JA, Ehde DM, Cardenas DD. Social environment moderates the association between catastrophizing and pain among persons with a spinal cord injury. Pain. 2003;106:19-25.

16. Raichle KA, Hanley M, Jensen MP, Cardenas DD. Cognitions, coping, and social environment predict adjustment to pain in spinal cord injury. J Pain. 2007;8:718-29.

17. Ullrich PM, Jensen MP, Loeser JD, Cardenas DD. Catastrophizing mediates associations between pain severity, psychological distress, and functional disability among persons with spinal cord injury. Rehabil Psychol. 2007;52:390-98.

18. Ullrich PM, Jensen MP, Loeser JD, Cardenas DD, Weaver FM. Pain among veterans with spinal cord injury. J Rehabil Res Dev. 2008;45:793-800.

19. Hanley MA, Raichle KA, Jensen MP, Cardenas DD. Pain catastrophizing and beliefs predict changes in pain interference and psychological functioning in persons with spinal cord injury. J Pain. 2008;9:863-71.

20. Perry KN, Nicholas MK, Middleton J. Spinal cord injury related pain in rehabilitation: a cross sectional study of relationships with cognitions, mood and physical function. Eur $\mathrm{J}$ Pain. 2009;13:511-17.

21. Molton IR, Stoelb BL, Jensen MP, Ehde DM, Raichle KA, Cardenas DD. Psychosocial factors and adjustment to chronic pain in spinal cord injury: replication and cross-validation. J Rehabil Res Dev. 2009;46:31-42.

22. Hirsh AT, Bockow TB, Jensen MP. Catastrophizing, pain, and pain interference in individuals with disabilities. Am J Phys Med Rehabil. 2011;90:713-22.

23. Finnerup NB, Jensen MP, Norrbrink C, Trok K, Johannesen IL, Jensen TS, et al. A prospective study of pain and psychological functioning following traumatic spinal cord injury. Spinal Cord. 2016;54:816-21.

24. Finnerup NB. Pain in patients with spinal cord injury. Pain. 2013;154(Supp 11):S71-S76.

25. Jensen TS, Baron R, Haanpaa M, Kalso E, Loeser JD, Rice AS, et al. A new definition of neuropathic pain. Pain. 2011;152:2204-5.

26. Störmer S, Gerner HJ, Gruninger W, Metzmacher K, Follinger S, Wienke $\mathrm{C}$, et al Chronic pain/dysesthesia in spinal cord injury patients: results of a multicentre study. Spinal Cord. 1997;35:446-55.

27. Siddall PJ, McClelland JM, Rutkowski SB, Cousins MJ. A longitudinal study of the prevalence and characteristics of pain in the first 5 years following spinal cord injury. Pain. 2003;103:249-57.

28. Werhagen L, Budh CN, Hultling C, Molander C. Neuropathic pain after traumatic spinal cord injury-relations to gender, spinal level, completeness, and age at the time of injury. Spinal Cord. 2004; 42:665-73.

29. Finnerup NB, Norrbrink C, Trok K, Piehl F, Johannesen IL, Sørensen JC, et al Phenotypes and predictors of pain following traumatic spinal cord injury: a prospective study. J Pain. 2014;15:40-8.

30. Finnerup NB, Otto M, McQuay HJ, Jensen TS, Sindrup SH. Algorithm for neuropathic pain treatment: an evidence based proposal. Pain. 2005;118:289-305 
31. Attal N, Mazaltarine G, Perrouin-Verbe B, Albert T. Chronic neuropathic pain management in spinal cord injury patients. What is the efficacy of pharmacological treatments with a general mode of administration? (oral, transdermal, intravenous). Ann Phys Rehabil Med. 2009;52:124-41.

32. Cardenas DD, Felix ER. Pain after spinal cord injury: a review of classification, treatment approaches, and treatment assessment. PMR. 2009;1:1077-90.

33. Siddall PJ. Management of neuropathic pain following spinal cord injury: now and in the future. Spinal Cord. 2009;47:352-9.

34. Teasell RW, Mehta S, Aubut JA, Foulon B, Wolfe DL, Hsieh JT, et al. A systematic review of pharmacologic treatments of pain after spinal cord injury. Arch Phys Med Rehabil. 2010;91:816-31.

35. Burke D, Fullen BM, Stokes D, Lennon O. Neuropathic pain prevalence following spinal cord injury: a systematic review and meta-analysis. Eur J Pain. 2017;21:29-44.

36. Budh CN, Hultling C, Lundeberg T. Quality of sleep in individuals with spinal cord injury: a comparison between patients with and without pain. Spinal Cord. 2005;43:85-95.

37. Budh CN, Osteråker AL. Life satisfaction in individuals with a spinal cord injury and pain. Clin Rehabil. 2007;21:89-96.

38. Ataoğlu E, Tiftik T, Kara M, Tunç H, Ersöz M, Akkuş S. Effects of chronic pain on quality of life and depression in patients with spinal cord injury. Spinal Cord. 2013;51:23-6.

39. Kilic SA, Dorstyn DS, Guiver NG. Examining factors that contribute to the process of resilience following spinal cord injury. Spinal Cord. 2013;51:553-7.

40. Taylor J, Huelbes S, Albu S, Gómez-Soriano J, Peñacoba C, Poole HM. Neuropathic pain intensity, unpleasantness, coping strategies, and psychosocial factors after spinal cord injury: an exploratory longitudinal study during the first year. Pain Med. 2012;13:1457-68

41. Heutink M, Post MW, Overdulve CW, Pfennings LE, van de Vis $\mathrm{W}$, Vrijens NL, et al. Which pain coping strategies and cognitions are associated with outcomes of a cognitive behavioural intervention for neuropathic pain after spinal cord injury? Top Spinal Cord Inj Rehabil. 2013;19:330-40.

42. Widerström-Noga E, Felix ER, Adcock JP, Escalona M, Tibbett J. Multidimensional neuropathic pain phenotypes after spinal cord injury. J Neurotrauma. 2016;33:482-92.

43. Widerström-Noga E, Biering-Sørensen F, Bryce T, Cardenas DD, Finnerup NB, Jensen MP, et al. The international spinal cord injury pain basic data set. Spinal Cord. 2008;46:818-23.

44. Melzack R. The McGill pain questionnaire: major properties and scoring methods. Pain. 1975;1:277-99.

45. Solomon Z, Benbenishty R, Neria Y, Abramovitz M, Ginzburg K, Ohry A, et al. Assessment of PTSD: validation of the revised PTSD inventory. Isr J Psychiatry Relat Sci. 1993;30:110-5.

46. Cohen S, Kamarck T, Mermelstein R. A global measure of perceived stress. J Health Soc Behav. 1983;24:385-96.

47. Spielberger CD, Gorsuch RL, Lushene RE. Manual for the statetrait anxiety inventory. Palo Alto, CA: Consulting Psychologists Press; 1970.

48. Lovibond SH, Lovibond PF. Manual for the depression anxiety stress scales. 2nd ed. Sydney: Psychology Foundation of Australia; 1995 .
49. Sullivan MJL, Bishop S, Pivik J. The pain catastrophizing scale: development and validation. Psychol Assess. 1995;7:524-32.

50. Tabachnick BG, Fidell LS. Using multivariate statistics. New York, NY: Harper Collins College Publishers; 1996.

51. Richards JS, Meredith RL, Nepomuceno C, Fine PR, Bennett G. Psycho-social aspects of chronic pain in spinal cord injury. Pain. 1980;8:355-66.

52. Finnerup NB, Johannesen IL, Sindrup SH, Bach FW, Jensen TS. Pain and dysesthesia in patients with spinal cord injury: a postal survey. Spinal Cord. 2001;39:256-62.

53. Budh CN, Lund I, Ertzgaard P, Holtz A, Hultling C, Levi R, et al Pain in a Swedish spinal cord injury population. Clin Rehabil. 2003;17:685-90.

54. Jenewein J, Wittmann L, Moergeli H, CrCreutzig J, Schnyder U. Mutual influence of posttraumatic stress disorder symptoms and chronic pain among injured accident survivors: a longitudinal study. J Traum Stress. 2009;22:540-8.

55. Levitan Y, Zeilig G, Bondi M, Ringler E, Defrin R. Predicting the risk for central pain using the sensory components of the international standards for neurological classification of spinal cord injury. J Neurotrauma. 2015;32:1684-92.

56. Margot-Duclot A, Tournebise H, Ventura M, Fattal C. What are the risk factors of occurrence and chronicity of neuropathic pain in spinal cord injury patients? Ann Phys Rehabil Med. 2009;52:111-23.

57. Melzack R, Casey KL. Sensory motivational, and central control determinants of pain. A new conceptual model. In: Kenshalo DR, editor. The skin senses. Springfield, IL: Charles C. Thomas; 1968. p. 423-43.

58. Treede RD, Kenshalo DR, Gracely RH, Jones AK. The cortical representation of pain. Pain. 1999;79:105-11.

59. Reading AE. A comparison of the McGill pain questionnaire in chronic and acute pain. Pain. 1982;13:185-92.

60. Price DD, Harkins SW, Baker C. Sensory-affective relationships among different types of clinical and experimental pain. Pain. 1987;28:291-301.

61. Ackerman MD, Stevens MJ. Acute and chronic pain: pain dimensions and psychological status. J Clin Psychol. 1989;45:223-8.

62. McGuire DB. Comprehensive and multidimensional assessment and measurement of pain. $J$ Pain Symptom Manage. 1992;7:312-9.

63. Koolhaas JM, Bartolomucci A, Buwalda B, de Boer SF, Flügge G, Korte SM, et al. Stress revisited: a critical evaluation of the stress concept. Neurosci Biobehav. 2011;35:1291-1301.

64. Gracely RH, Geisser ME, Giesecke T, Grant MAB, Petzke F, Williams DA, et al. Pain catastrophizing and neural responses to pain among persons with fibromyalgia. Brain. 2004;127:835-43.

65. Sullivan MJ, Lynch ME, Clark AJ. Dimensions of catastrophic thinking associated with pain experience and disability in patients with neuropathic pain conditions. Pain. 2005;113:310-5.

66. Cohen S, Janicki-Deverts D, Miller GE. Psychological stress and disease. JAMA. 2007;298:1685-7. 